\title{
The Triangle of Representation
}





\section{The \\ Triangle of \\ Representation}

Christopher Prendergast

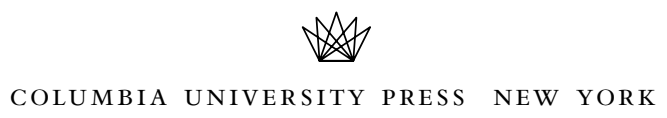




\section{Columbia University Press \\ Publishers Since 1893 \\ New York Chichester, West Sussex}

Copyright (C) 2000 Columbia University Press

All rights reserved

Library of Congress Cataloging-in-Publication Data

Prendergast, Christopher.

The triangle of representation / Christopher Prendergast. p. cm.

Includes bibliographical references and index.

ISBN O-23I-I2090-7 (cloth : alk. paper)

ISBN 0-23I-I209I-5 (pbk. : alk. paper)

I. Representation (Philosophy) 2. Culture. I. Title.

Bio5.R4 $\mathrm{P}_{74} 2000$

IIO-de2I OO-02265I

Casebound editions of Columbia University Press books are printed on permanent and durable acid-free paper.

Printed in the United States of America

Designed by Audrey Smith

$$
\begin{aligned}
& \text { c IO } 98765432 \text { I } \\
& \text { p IO } 98765432 \text { I }
\end{aligned}
$$


For Gita and Clea 
